\title{
On the Problems and Countermeasures of Rural Ecological Culture Construction from the Perspective of the Strategy of Rural Revitalization
}

\author{
Wen-He LIN ${ }^{1, a}$, Wen-Bao WANG ${ }^{2, b,{ }^{*}, \text { Lu-Bin KE }}{ }^{3, c}$ \\ ${ }^{1,3}$ College of Management, Ecological Civilization Research Center of Fujian Social Sciences \\ Research Base, Fujian Agriculture and Forestry University, Fuzhou, China \\ ${ }^{2}$ School of Management, Fujian University of Technology, Fuzhou, China \\ a253062775@qq.com, ${ }^{\text {b2 } 231057452 @ q q . c o m,{ }^{c} 735165745 @ q q . c o m}$
}

Keywords: Rural ecological culture, "Culture-adaptability" village strategy.

\begin{abstract}
As a comprehensive organic system, rural ecological culture is constituted by three basic elements- rural ecological culture products, rural ecological culture activity mode and rural ecological culture concept. Such problems as the insufficient ecology awareness, a shortage of organization strength, a shortage of talents, the insufficient innovation ability, low industrialization quality and excessive commercialization of development happen to exist in the rural ecological culture. As a result, it's a necessity to promote "culture-adaptability" village strategy and realize optimization of multiple paths for the sake of better forming the "beautiful village" culture.
\end{abstract}

\section{Introduction}

The 19th Communist Party of China(CPC) National Congress report focuses on "countryside, agriculture and farmer" with the implementation of rural revitalization strategy firstly proposed and the general requirements of "Industrial Prosperity, Ecological Livable, Rural Civilization, Effective Governance and Rich Life" put forward. "Ecological Livable " is the key link of rural revitalization, requiring not only the economic, social and cultural revitalization but also governance system innovation and progress in ecological civilization. It is an aggregate concept regarding overall revitalization. How to make countryside culture return and provide power for rural revitalization and how to make excellent essences in the farming culture become the guideline for the construction of ecological civilization and make village become an ecological and livable home shall be taken into account. "Culture-adaptability" rural reconstruction is an important carrier and a concrete embodiment regarding the implementation of the 19th CPC National Congress report as well as the important content of the socialist new countryside construction.

\section{Connotation and Levels of Rural Ecological Culture Construction}

\section{Connotation of Rural Ecological Culture Construction}

In a narrow sense, the ecological culture refers to the social ideology, human spirit and social system directed by the ecological value[1] . Construction of rural ecological culture covers contents in many fields like rural economy, society, system and culture. It covers various discipline fields from the material culture production (including agricultural production, processing of agricultural product and production of rural industrial enterprises) to the construction of the system culture (including construction of rural grass-roots organizations, construction of rural system and construction of rural social organization) and to the construction of rural culture (in a narrow sense). Especially, the construction and development of rural culture pertain to development direction and strategy of rural economy and society [2] .

\section{Levels of Rural Ecological Culture Construction}

As a system, the rural ecological culture is in possession of an internal special structure. According to Marxism, it's deemed that formation and development of the rural culture as well as changes in its form are determined ultimately by the development of the farmer production mode and its form 
changes[3] . The rural culture generated during the process of transforming agriculture and human themselves by farmers falls into an organic system. The organic system consists of three basic elements, that is, rural ecological culture product, rural ecological culture activity mode and rural ecological culture concept [4] .

Rural ecological culture product is the surface element of the rural ecological culture system. It includes material products and spiritual products. Rural culture activity mode refers to the "activity mode" or "activity pattern" presented through the material products and spiritual products created by farmers. Rural ecological culture is embodied by ecological products of the rural culture as well as in the production process of the products and the method of producing products. From the perspective of generation process of rural ecological culture, the rural culture involves conservation and delivery of the farmer activity mode (experiences). From the perspective of the influences of the rural ecological culture on human, the rural ecological culture helps people master the basic activity mode instead of providing existing "consumer goods" [4] . The process of people mastering the rural ecological culture is that they learn and inherit specific activity mode and get the basic ability of implementing various necessary activities.

Rural ecological culture concept refers to the basic understanding and view of people grasping such rural culture which involve the outer world, themselves and the relationship between themselves and the outer world. On one hand, it is the symbolization (formalization) and theorization of the activity mode. On the other hand, rural ecological culture concept is the basis for enabling activity mode to operate (combine with human). Thus it's the core factor of rural ecological culture system. Because people have different understandings and perspectives concerning the outer world, themselves and the relationships between themselves and the outer world, different rural culture activity modes and rural ecological culture products arise.

Rural ecological culture products lie at the outer layer of the rural culture system and are the phenotype part of rural culture and also the concrete embodiment of the rural ecological culture activity mode as well as the rural ecological culture concept. Rural ecological culture activity mode lies at the middle layer of the rural ecological culture system, becoming the intermediate link for communication, conversion and interaction between outer layer and inner layer of rural ecological culture system and the main mark for distinguishing the differences between different rural ecological cultures. Rural ecological culture concept lies at the inner layer of the rural culture system and is the crypto type part of rural ecological culture. After the combination of three basic elements, the entirety of rural ecological culture system is formed. Interaction between them drives rural ecological culture system to evolve and develop.

\section{Multiple Problems of Rural Ecological Culture}

\section{Lack of Ecological Culture Consciousness of Subject Villagers}

Due to the limitation of the economic condition and a lack of ecological science knowledge and feudal superstition culture which is accumulated in the traditional countryside for thousands of years mingled into rural ecological culture "growth" space, rural residents get used to pursuing and paying more attention to short-term economic benefits and ignoring the long-term comprehensive benefits of social, economic and ecologic environments in the ecological culture construction. In addition, influenced by traditional moral idea, the mentality of small-farm agriculture and other traditional concepts, the degree of public participation in promotion of ecological culture is low [5] . On account of concepts about traditional code of conduct in the traditional moral concept, such activities like ecological environment protection activities, supervision, reporting and monitoring based on development of extensive people power are difficult to be effectively implemented. Due to the mentality of small-farm agriculture, all rural villagers lack the ecology awareness and overall viewpoint and fail to comprehend the relationships between individual behaviors and the change in the whole ecology with a low degree of participation in ecological culture promotion by villagers. Most of villagers will choose to give up if those ecological environmental protection activities result in inconveniences or require them to give up some vested interests. Generally speaking, the rural 
ecological culture is still in the initiate stage of construction, and the ecological culture concept fails to completely enjoy popular support and rural residents still take on a mental burden of heavy historical culture.

\section{Short of Organization Strength on the Construction of Rural Ecological Culture}

At present, the countryside still lacks professional organizations and institutions to undertake the publicity and popularization of rural ecological environment protection. The related departments (such as environmental protection, culture, education and publicity department) carry out publicity independently and do things in their own way without cooperation. The countryside lacks unified agency and professionals engaging in ecological culture propaganda, so there is no lasting, deep and effective popularization and publicity on the ecological scientific knowledge. Furthermore, although civil commonweal organizations are relatively active and civil ecological commonweal organizations play a key role of startup, organization, coordination and supervision in the environmental protection activities organized by the public, the civil ecological commonweal organizations in the rural area still lack, resulting in the fact that the environmental protection activities organized by rural people fail to be initiated and implemented in an organized way.

\section{Related Systems of Rural Ecological Culture need to be Perfected}

Construction of rural ecological culture system is a systematic procedure which involves every aspect of rural life, thus healthy and orderly ecological culture construction process needs to be guaranteed by perfect management system [6] . And existing management system of rural ecological culture is almost in the blank stage and is badly in need of correct guidance and specification. Furthermore, on one hand, due to the restriction of economic condition and knowledge finiteness, no sufficient fund is put into ecological culture construction involving ecological education, pleasant living environment publicity and infrastructure of ecological culture popularization in the countryside, as a result, the implementation of ecological culture construction management work becomes more difficult; on the other hand, there are still some township enterprises with technological backwardness, wasting of resources and serious environmental pollution in partial rural areas whose negative external behaviors fails to be well supervised by related departments, resulting in ecological culture construction by people weakened.

\section{Short of Talent and Insufficient Innovation Ability}

As a new civilization form, ecological civilization requires getting rid of the value orientation of traditional industrial civilization-"technical rationality coming first" and all "mechanisms" evaluated by economic criterion. Rather, the resource and environment problems can be settled by development of a series of environmentally friendly technologies and high and new technologies. Decrease or even elimination of negative effects of technologies can be achieved through technology improvement and rational usage of technologies. Sustainable development of traditional industries also can be realized by transformation of green technology. The fact that the technology supporting system of rural ecological civilization hasn't be established yet, team composed by ecological science popularization and education talents with comprehensive knowledge and first-class quality as well as scientific research talents boosting green and innovative technology lack, finance and taxation as well as investment and financing policies making for construction of ecological civilization are imperfect and mechanism of innovation fails to be formed directly causes many ecological engineering projects in the countryside fail to be impelled. Rural planning and residential designers become the bottleneck in the process of beautiful countryside construction and rural tourism development, so rural architecture design and rural planning talents urgently need to be cultivated. In accordance with Central Document No.1, institutions of higher education and vocational colleges are encouraged to establish related specialties and courses such as rural planning and construction as well as rural housing design and cultivate a batch of professionals and give aid to a batch of rural craftsmen. 


\section{Low Industrialization Quality and Excessive Commercialization of Development}

Although implementation of appropriate tourism development can provide funds for protection of intangible cultural heritage and the market value incurred by it may motivate people to protect the intangible cultural heritage, giving rise to inheritance and innovation of intangible culture, once some places are developed for the development, the local culture core is lost with emergence of crooked promotion, resulting in performization, commercialization and even vulgarization of intangible cultural heritage, diversity and cultural space of intangible cultural heritage destroyed and even mechanical application, creating something new and original and making some false national cultures not existing locally. Inundant business development of intangible cultural heritage in the tourism industry leads to gradual deterioration of national culture value.

\section{Strategies about Establishment of "Culture-Adaptability" Village Based on Multidimensional Observation}

\section{Rural Civilization Quality Engineering Taking Ecological Culture Construction and Education \& Training as Priority}

By widely promoting publicity and education activities with various forms and rich contents, ecological education base is conducted to permeate ecological education concept to villagers and cultivation of rural civilization is taken as important content of beautiful countryside construction in light of the planning of rural ecological culture. In the village-level cultural education places like the activity center of ecological culture construction, culture wall and culture capsule, the ecological civilization knowledge propaganda and training activities with various forms are implemented to form new fashion of rural ecological civilization. It's necessary to make great efforts to make each civilized and ecological village own one room for publicizing culture as well as related recreational and sports activity facilities. Harmonious rural ecological culture system is constructed. It's necessary to respect rural custom, protect traditional excellent culture in the countryside and contain recovery of waste matter in the traditional culture. For protection of traditional culture in the countryside, collection of specimen and construction of rural culture museum shall be conducted because "no dignity of life arises in case of no collective memory, sense of belonging or identity", causing new countryside just an abandoned shell" ${ }^{[7]}$. Traditional culture in the countryside can be under the regional protection based on the cultural ecology. It should be restrained in a particular area without changing local production and life environments. Protection of original distinctive culture is conducted. Social resources are integrated and semi-official or civil social organization for environmental protection is established to enable social organization to take an active part in ecological culture construction, actively propagandize construction of ecological culture as well as contribute ideas and exert efforts for the government.

\section{Enrich Villagers' Amateur Cultural Life and Improve Farmers' Spiritual Outlook}

Rural culture facilities, libraries and recreational and sports activity centers are constructed. Villagers' living habit-mainly participating in playing Mahjong and playing card in the spare time is changed and villagers are led to pay attention to domestic and overseas events, agricultural technology, environmental protection, education and other living habits which can help them promote individual quality. For villages and towns with limited funding conditions and disperse villagers' domiciles, "mobile library in the countryside" can be adopted to save cost and meet villagers' demand of reading books. Such activities as performing drama and popularizing technology and law knowledge in the countryside shall be often conducted in order to make villagers absorb healthy spiritual nutrition from the drama, generalize scientific farming and scientific cultivation technique as well as try hard to enable villagers to know the laws and abide by them based on actual conditions of farmers and countryside. Cultural activities (including dragon and lion dance, gong and drum, land boat, stilts and other traditional cultural and artistic performances) suitable for farmers shall be implemented at Spring Festival, Lantern Festival, etc.. And other slack seasons shall be also used to organize farmers to implement literary and artistic 
activities liked by farmers, such as fun sports meeting, opera and singing contest so as to enrich farmers' cultural life and improve farmers' artistic appreciation. In the plan, the following cultural activities shall be implemented based on actual conditions of the countryside and village.

\section{Cultivation of Rural Ecological Culture Carriers Based On Taking Excavation of Culture Connotation as the Target}

Multi-type ecological culture carriers are cultivated in premise of relying on the rural ecological culture. 1. Construction of ecological culture demonstration village is conducive to driving the ecological process of nearby villages. Main forms of expressing ecological culture demonstration village include forest folk culture village, old-age house ecological culture village, coastal fishing and farming culture village, culture village in old revolutionary base areas and island ecological culture village, etc. 2. Forest culture educational base. For construction of rural ecological culture, it's necessary to deeply dig such forest resources as forest park, natural scenic spot and forestry center with advantageous ecological environment, good traffic conditions and abundant connotation, building a corresponding themed forest culture education display center and form a forest culture education base characterized by creation of natural ecology and cultural science popularization and education and integrating popularization of science, propaganda and education, leisure vacation as well as cultural transmission. 3. Forest ecological tourism culture. By relying on recreation value landscape and scenic spot, taking foresters and large-scale growers as business entities, making full use of animal and plant resources and local featured products and integrating forest culture and folk custom, visitors are provided with cheap and fine ecologically friendly tourism products involving tourism element services such as eating, living, tour, recreation and shopping. 4. Agriculture ecology experience culture. Deep development of agricultural landscape, settlement landscape and countryside landscape is conducted and new ecological and cultural tourism form with ecological functions of leisure and seeking knowledge is formed based on extension crossing with tourism industry. Its main forms include farming culture experience, picking garden culture, etc. 5. Embodiment of wetland ecological culture. In general, the development of wetland ecological culture is in the initial stage and there is a large development space. It's necessary to fully enrich wetland resources, carry out protection and restoration of wetland resources, landscape construction and ecological culture construction so as to provide leisure experience places with coastal features for rural ecological culture. Its main forms cover wetland culture display, wetland ecological culture experience area, etc.

\section{Enlarging the Industry and Boosting Industrialization Exploitation of Rural Ecological Culture}

Firstly, it's necessary to increase exploitation and utilization of rural culture resources. "Materialization" and "activation" of rural culture heritage resources and characteristic cultural resources are conducted and ecological agriculture, ecological characteristic culture resources, cultural talent resources are adjusted and classified for arrangement, registration and digital preservation. The museum collection display mode, live-action tourism mode, stage performance mode, publishing and recording mode as well as teaching and learning training mode are adopted to realize wide spread and adequate protection and utilization. Secondly, it's necessary to take several measures simultaneously and put efforts to raise the level of cultural consumption. It's necessary to facilitate culture consumption. In addition to striving to develop economy and raising the level of the masses' income, it's necessary to start from cultivation and increase of residents' cultural consumption concept and greatly improve residents' cultural quality by public opinion guidance, interest cultivation and quality-oriented education as well as provide richer and more splendid cultural products and services to enable people to gradually experience the nicety of spiritual enjoyment. Thirdly, it's necessary to develop rural ecological culture products and service. The rural culture resources can be used as materials. It's necessary to create literary works, produce public cultural products (such as development of rural stoneware, woodware, bambooware, rattan articles, straw plaited article, paper cuttings, clay figurines, tile carving and other native famous artware) as well as organize farmers to process, product and operate characteristic culture products. Rural 
production, life, folk-custom, farmhouse, leisure, life nourishing, field systems are connected to build the rural culture industry chain. Performances and competition activities such as rural song and dance, rural sports, rural amorous feelings, rural marriage customs, rural tourism, rural farming and weaving and rural feeding are organized and cultural service with full-bodied country flavor is provided. Activities such as rural leisure and recreation, local flavor food and feeling country life are implemented. Exhibition of rural culture and historic culture is conducted to vividly and systematically reflect the characteristics and history of farming culture, nomadic culture as well as fishing and hunting culture. The rural culture educational base for primary and secondary school students shall be established.

\section{Cultivation of Cultural Talent Team and Encouraging Grass-Roots Masses to Participate in Protection and Inheritance}

"People" are culture creators and carriers, and culture inheritance and development depend on excellent persons. For this purpose, firstly, it's necessary to vigorously develop cultural talent team. Talents at different levels based on different cultural arts shall be cultivated and specialized craft places shall be built to facilitate inheritance of handwork culture. Creativity of literary and art workers shall be respected and enough creation space shall be given to them to promote the artistic level and aesthetic taste of cultural works. Secondly, it's necessary to strictly control the quality of cultural cadre talent, improve professional quality and management ability of grass-roots cultural workers, strengthen training guidance, actively cultivate cultural backbone of farmers as well as a batch of "countryside, agriculture and farmer" staff who know agriculture and love village and villagers as well as complete talent introduction work such as "college-graduate village official", "three supports and one assistance", "college student volunteers to the West Program" and "new youth going to the countryside". Moreover, it's necessary to cultivate local "county sages" going back home to act as leaders for becoming rich and be bold to conduct directed education of a local village cadre reserve team based on priority of source of students knowing agriculture and loving countryside and farmers in order to lay a solid foundation for better implementing rural revitalization strategy in the rural area. Thirdly, it's necessary to fully mobilize the public to participate. Extensive farmers are the subjects for construction of new countryside as well as innovation of rural ecological culture. It's necessary to stimulate and cultivate farmers' culture consciousness and subjective effects. Cultural self-consciousness of the masses is the foundation and guarantee for the protection of intangible cultural heritage. Subjective effects of villagers can be exerted in the form of folk cultural organization and historical context. Art or manual skill are inherited by organizing various folk cultural activities which building the platform for cultivation of rural culture talents.

\section{Acknowledgements}

This project was supported by the Major Projects of Social Sciences Research Base of Fujian under grant 2016JDZ039, Outstanding Youth Scientific Research Talent Program Of Fujian Province In 2017"Study on the Growth Mechanism of Cultural Enterprises from the Perspective of Innovation Ecology", Fujian Agriculture and Forestry University Science and Technology Innovation Fund in 2017 under grant CXZX2017405 and the Young Outstanding Talents Fund Project of Fujian Agriculture and Forestry University under grant xjq201636.

\section{References}

[1] C.S Zhang. Forward Excellent Ecological Culture and Propelling Construction of Ecological Civilization[J]. Socialist Forum,2017(5)

[2] G.J.Wang,W.H. Xiang. Urban and Rural Ecological Planning[M]. Chinese Forestry Press, 2015,pp.341.

[3] Y.Chen. Difference Sequence Transmission and Reconstruction of Rural Culture Transition 
under Dual Structure xinwenjie.zazhi.com.cn/ 2017(9),PP.44-48.

[4] W.T.Zheng ,Y.W. Hua. Research about the Development of Beijing Rural Culture under the Field of Vision of World City.Chinese Agriculture Press,(2013)45.

[5] D.Zou.The theory of main body in the cultivation of ecological culture [J]. Journal of Beijing Forestry University (Social Sciences Version) 2017, 16(2),pp.1-7.

[6] Z.R. Ni, G.F.Ye and Z.M.Hong. Practice of Ecological Civilization in the Construction of New Countryside in Xiamen . Xiamen University Press( 2012) 132.

[7] H.K.Wu,J. Xu. Construction of Ecological Agriculture and Beautiful Countryside. China Agricultural Science and Technology Press(2015) 158. 